ISSN 1112-9867

http://www.jfas.info

\title{
RECOVERY OF COPPER(II) AND CHROMIUM(III) FROM NITRATE MEDIUM WITH SALICYLIDENEANILINE DISSOLVED IN 1-OCTANOL
}

\author{
A. Guerdouh* and D. Barkat \\ Laboratory of chemical molecular and environment, Department of Industrial Chemistry, \\ Faculty of Science and Technology, Biskra University, 07000 Biskra, Algeria
}

Received: 17 January 2016 / Accepted: 14 Febraury 2016 / Published online: 01 May 2016

\begin{abstract}
The solvent extraction of copper(II) and chromium(III) from nitrate medium with salicylideneaniline (HL) is studied as a function of various parameters: $\mathrm{pH}$, concentration of salicylideneaniline, contact time and the nature of anoin (nitrate and sulfate) in aqueous phase. Chromium(III) is not extracted by salicylideneaniline diluted in 1-octanol. Copper(II) is only extracted by salicylideneaniline and it was found that the highest extractability achieved to $95 \%$ at $\mathrm{pH} 4.9$, The stoichiometry of the extracted species was determined by using the method of slope analysis. Elemental analysis, UV-vis and IR-spectra were used to confirm the structure. It is found that the copper (II) is extracted as $\mathrm{CuL}_{2} \cdot 2 \mathrm{H}_{2} \mathrm{O}$ Their equilibrium constant, distribution coefficient, percentage extraction $(\% E)$ and free energy are also calculated.
\end{abstract}

Keywords: solvent extraction; copper(II); chromium(III); salicylideneaniline.

Author Correspondence, e-mail: amelguerdouh@yahoo.fr

doi: http://dx.doi.org/10.4314/jfas.v8i2.15

\section{INTRODUCTION}

Solvent extraction system is one of effective technique used for separation of metal cations from aqueous solutions $[1,2]$. It is a suitable method for prevent and protect environment from pollution. 
Complexes of some metal ions with Schiff's bases have a big importance in organic synthesis and catalysis because of their variety of applications such as: biological, clinical, analytical, physiological and pharmacological activities [3, 4]. The Schiff's bases ligands act as a good extracting agents for the transition of metal ions $[5,6]$.

Solvent extraction of chromium and copper using Schiff's bases derived from terephthaldialdehyde and 5-amino-2-methoxy-phe is studied by Al Zoubi, Kandil and Chebani [7]. It was found that the extraction efficiency of ligand for metals is in the order $\mathrm{Cu}^{2+}>\mathrm{Cr}^{3+}$. Almi et al .[8] found that salicylideneaniline dissolved in chloroform extracts capably copper(II) from sulfate medium. They were confirmed that the extracted species in organic phase are $\mathrm{CuL}_{2}$ with $\mathrm{CuL}_{2}(\mathrm{HL})$. On the other hand, there were no research about the solvent extraction of chromium(III) with salicylideneaniline.

The present paper describes the results obtained from the solvent extraction of copper (II) and chromium(III) from nitrate medium by salicylideneaniline dissolved in 1-octanol. Our interest is to determinate the stoichiometric coefficient of the extracted species from nitrat medium and investigated the effect of anoin type (nitrate and sulfate) on these extraction systems. In addition, a study on the chromium(III) extraction was realised in ordre to compare the solvent extraction of divalent and trivalent metal ions using salicylideneaniline.

\section{EXPERIMENTAL}

\subsection{Reagents and solutions}

Salicylideneaniline (HL) was synthesized in our laboratory by refluxing salicylaldehyde with the aniline and was purified by recrystallisation from ethanol [9]. The structure of salicylideneaniline shows in figure 1. Copper nitrate (Biochem), chromium nitrate, copper sulfate (Biochem), sodium nitrate and sodium sulfate (Biochem) were used without further purification. 1-octanol was employed as the organic solvent. The ionic strength of the aqueous medium was assumed to be unity $\left(\left[\mathrm{NaNO}_{3}\right]=1 \mathrm{M}\right)$. Aqueous phase: $\left[\mathrm{Cu}^{2+}\right]=1.57 \times 10^{-3} \mathrm{M}$, $\left[\mathrm{Cr}^{3+}\right]=1.92 \times 10^{-3}$ to $10^{-2} \mathrm{M}$. 


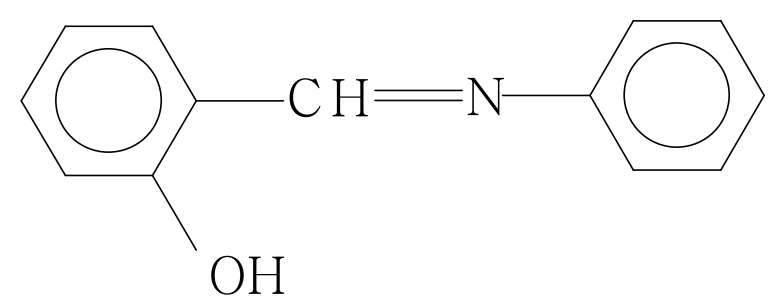

Fig.1. Structure of salicylideneaniline.

\subsection{Extraction and analytical procedures}

Experiments were carried out by shaking equal volumes $(25 \mathrm{ml})$ of both phases in thermostatted vessels. The time required to reach the equilibrium state was $30 \mathrm{~min}$. However for chromium extraction both phases were contacted several hours. The $\mathrm{pH}$ of the aqueous phase was adjusted by adding the necessary amount of $0.1 \mathrm{M} \mathrm{NaOH}$. Then, after the two phases were separated completely, concentrations of the copper(II) and chromium(III) remaining in the aqueous phase were determined photometrically at $820 \mathrm{~nm}$ and $570 \mathrm{~nm}$ respectively using a Philips UV-VIS SP6-36. The metal ion concentrations in the organic phase were calculated from the difference between the metal ion concentrations in the aqueous phase before and after extraction. All the experiments were carried out at constant temperature $\mathrm{T}=25^{\circ} \mathrm{C}$.

\section{RESULTS AND DISCUSSION}

\subsection{General treatment of extraction equilibrium of metal with salicylideneaniline}

The extraction of metal with salicylideneaniline from nitrate media may be described by the following equilibrium:

$$
\mathrm{M}_{\mathrm{aq}}^{n+}+(n+m)(\mathrm{HL})_{\mathrm{org}} \underset{\mathrm{ex}}{\rightleftharpoons}\left(\mathrm{ML}_{n}(\mathrm{HL})_{m}\right)_{\text {org }}+n \mathrm{H}^{+}
$$

Where, equilibrium constant $\mathrm{K}_{\mathrm{ex}}$ is defined as equation (2) and it can be rewritten as equation (3) by using the distribution ratio, $D$ of metal.

$$
\begin{aligned}
\mathrm{K}_{\mathrm{ex}} & =\frac{\left[\left(\mathrm{ML}_{n}(\mathrm{HL})_{m}\right)\right]_{\mathrm{org}}\left[\mathrm{H}^{+}\right]^{n}}{\left[\mathrm{M}^{n+}\right]_{\mathrm{aq}}[\mathrm{HL}]_{\mathrm{org}}^{(n+m)}} \\
\log D & =(n+m) \log [\mathrm{HL}]_{\mathrm{org}}+n \mathrm{pH}+\log \mathrm{K}_{\mathrm{ex}}
\end{aligned}
$$

Where the distribution coefficient, $D$, is defined as the ratio between the concentration of 
metal in organic and aqueous phase. The species in the aqueous and organic phases are designated by the subscripts aq and org, respectively. Other parameters are defined as:

$\mathrm{M}: \mathrm{Cu}^{2+}$ or $\mathrm{Cr}^{3+}, n=$ cationic charge, $m=$ number of salicylideneaniline molecules contained in the complex.

The equilibrium slope method has been used to analyze the experimental data for each extraction system. The stoichiometries of the extracted species were determined on the basis of some equations derived from equation (3). With a predetermined salicylideneaniline concentration in the organic phase and if only $\left(\mathrm{ML}_{n}(\mathrm{HL})_{m}\right)$ is the extractable species in the extraction system, the plot of $\log D$ versus $\mathrm{pH}$ at constant concentration of the extractant should yield a straight line with a slope of $n$. In addition, the plot of $\log D$ versus $\log$ [HL] at constant $\mathrm{pH}$ should give a straight line of slope $(n+m)$, from which the value of $m$ may be calculated. Therefore, the logarithmic values of $\mathrm{K}_{\mathrm{ex}}$ of metal can be calculated using equation (3). Also the percentage extraction $(\% E)$ of metal is calculated by the following equation:

$$
\% E=\frac{D}{D+1} \times 100
$$

\subsection{Analysis of the extraction equilibrium of copper(II) with salicylideneaniline dissolved in 1-octanol}

\subsubsection{Effect of pH}

In order to investigate stoichiometry of the extracted species in organic phase and to find out which chemical equation applies to the extraction process, a series of copper(II) extractions are carried out with salicylideneaniline.

According to equation (3) the relationships $\log D$ versus $\mathrm{pH}$ are determined at a constant [HL] in 1-octanol. The results are shown in figure 2, linear relations are observed with the slope of two $(n=2)$. This means that two protons are liberated during the extraction process, confirming that the extracted species in organic phase is $\mathrm{CuL}_{2}(\mathrm{HL})_{\mathrm{m}}$. The curves obtained show that the extraction of copper(II) increases with the concentration of salicylideneaniline. 


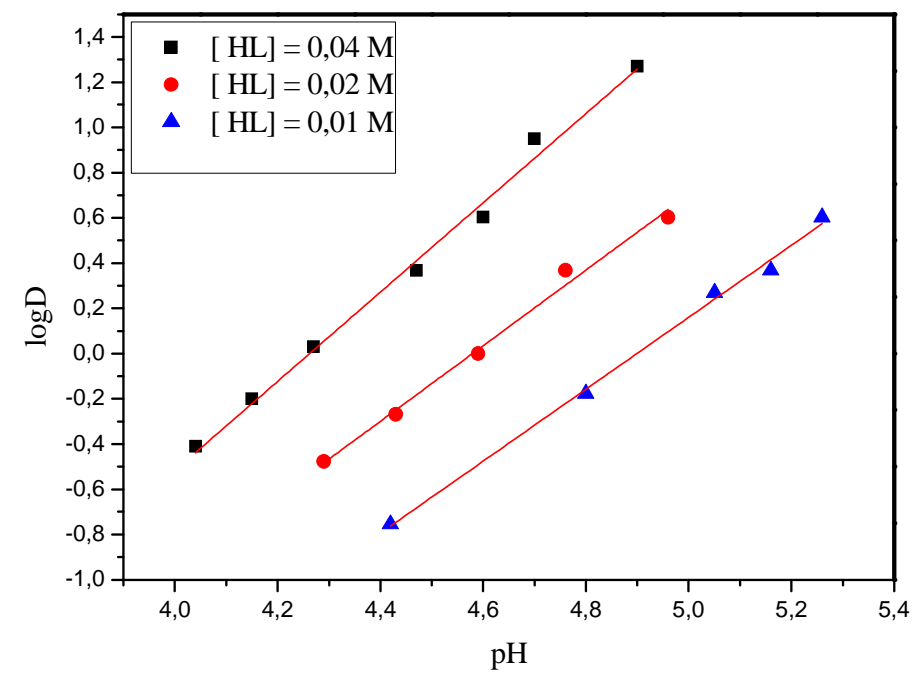

Fig.2. Distribution coefficient $\log D$ against $\mathrm{pH}$ at the extraction of copper(II) with salicylideneaniline dissolved in 1-octanol

Percentage extraction $(\% E)$ and the distribution coefficient $(D)$ were calculated to determine the extracting capability of salicylideneaniline diluted in 1-octanol (Tables 1). The distribution coefficient $(D)$ and extraction percentage $(\% E)$ increased with increasing $\mathrm{pH}$ of aqueous solution. The highest extractability for copper(II) was achieved to $95 \%$ at $\mathrm{pH}=4.90$.

Table 1. The distribution coefficient $(D)$ and extraction percentage $(\% E)$ for extraction of copper(II) with salicylideneaniline $(0.04 \mathrm{M})$ dissolved in 1-octanol.

\begin{tabular}{ccccc}
\hline $\mathbf{p H}$ & $\begin{array}{c}{\left[\mathbf{C u}^{2+}\right]_{\mathbf{a q}} \mathbf{x} \mathbf{1 0}^{-3}} \\
(\mathbf{m o l} / \mathbf{L})\end{array}$ & $\begin{array}{c}{\left[\mathbf{C u}^{2+}\right]_{\text {org }} \mathbf{x 1 0}} \\
(\mathbf{m o l} / \mathbf{L})\end{array}$ & $\boldsymbol{D}$ & $\boldsymbol{\%} \boldsymbol{E}$ \\
\hline $\mathbf{4 , 0 4}$ & 1,18 & 0,38 & 0,32 & 24,77 \\
$\mathbf{4 , 1 5}$ & 1,02 & 0,54 & 0,53 & 34,80 \\
$\mathbf{4 , 2 7}$ & 0,78 & 0,78 & 0,99 & 49,84 \\
$\mathbf{4 , 3 8}$ & 0,62 & 0,94 & 1,49 & 59,87 \\
$\mathbf{4 , 4 2}$ & 0,55 & 1,01 & 1,84 & 64,89 \\
$\mathbf{4 , 4 7}$ & 0,47 & 1,09 & 2,32 & 69,90 \\
$\mathbf{4 , 5 3}$ & 0,39 & 1,17 & 2,98 & 74,92 \\
$\mathbf{4 , 6 0}$ & 0,31 & 1,25 & 3,98 & 79,93 \\
$\mathbf{4 , 7 0}$ & 0,15 & 1,41 & 8,91 & 89,9 \\
$\mathbf{4 , 9}$ & 0,007 & 1,5 & 18,62 & 95 \\
\hline
\end{tabular}




\subsubsection{Effect of salicylideneaniline concentration}

A study on the effect of salicylideneaniline concentration on copper(II) extraction enables us to determine the number of salicylideneaniline molecules involved in the extracted species. This effect was investigated by making a series of copper(II) extractions at various [HR] dissolved in 1-octanol.

According to equation (3), Plots of $\log D$ versus $\log [\mathrm{HL}]_{\text {org }}$ in 1-octanol at constant $\mathrm{pH}$ were linear with the slope about of 2 , as shown in figure 3 , that is, $(2+m)=2$ or $m=0$. Consequently, the composition of the extracted species is $\mathrm{CuL}_{2}$. Similar complexes were obtained by many authors on the extraction of copper(II) with Schiff bases[10] . Therefore, equations (1) and (3) could be rewritten as:

$$
\begin{gathered}
\mathrm{Cu}_{\mathrm{aq}}^{2+}+2(\mathrm{HL})_{\mathrm{org}} \stackrel{\mathrm{K}_{\mathrm{ex}}}{\rightleftharpoons} \mathrm{CuL}_{2, \mathrm{org}}+2 \mathrm{H}^{+} \\
\log D=2 \log [\mathrm{HL}]_{\mathrm{org}}+2 \mathrm{pH}+\log \mathrm{K}_{\mathrm{ex}}
\end{gathered}
$$

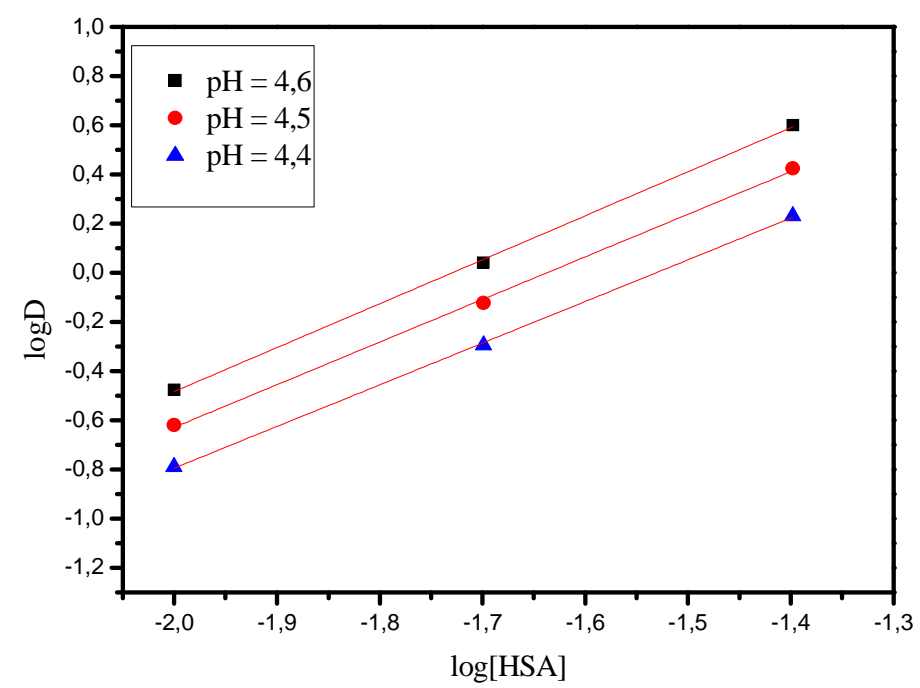

Fig.3. Determination of the number of salicylideneaniline involved in the extracted species in 1-octanol

According to equation (5), the logarithmic value of $\mathrm{K}_{\mathrm{ex}}$ of copper(II) is calculated to be/ $\log \mathrm{K}_{\mathrm{ex}}=-5.80$.

The extractability of copper(II) was evaluated as a function of salicylideneaniline concentration, as shown in Table. 2, the percentage extraction (\%E) of copper(II) and the distribution coefficient $(D)$ increase with the concentration of salicylideneaniline. 
Table 2. Effect of concentration of HL on the extraction percentage (\%E) of copper (II) at $\mathrm{pH}=4,5$.

\begin{tabular}{cccc}
\hline$[\mathbf{H L}]$ & $\log \boldsymbol{D}$ & $\boldsymbol{D}$ & $\mathbf{c} \boldsymbol{E}$ \\
\hline $\mathbf{0 , 0 1}$ & $-0,62$ & 0,23 & 19,28 \\
$\mathbf{0 , 0 2}$ & $-0,12$ & 0,75 & 42,88 \\
$\mathbf{0 , 0 4}$ & 0,42 & 2,64 & 72,58 \\
\hline
\end{tabular}

\subsubsection{Effect of contact time}

As seen in figure 4, the effect of time on the degree extraction of copper (II), was studied at constant $\mathrm{pH}$. This parameter was varied from 5 to 120 minutes. The extraction percentage $(\% E)$ increased with increasing of contact time between the aqueous and organic phase, it confirms that this Schiff base is decomposing during extraction. The highest extractability for copper(II) was achieved at $95 \%$ after 30 min and hence can be considered as an optimal time value.

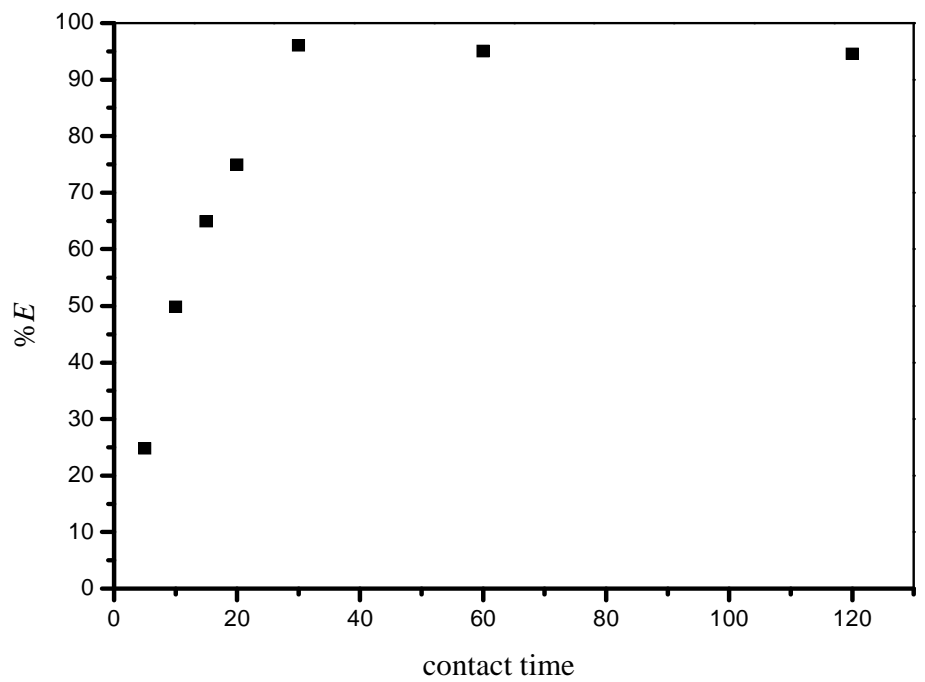

Fig.4. Effect of contact time on the extraction percentage (\%E) of copper (II)

\subsubsection{Effect of anion type on the copper extaction with salicylideneaniline}

Figure 5 represents plots of $\log \mathrm{D}$ versus $\mathrm{pH}$ obtained during the extraction of copper(II) from aqueous solutions containing various anions with salicylideneaniline. The data indicate that there was a difference on the extraction efficiency between nitrate and sulfate anions. The 
copper extraction from sulfate medium occurred at higher $\mathrm{pH}$ values. As it is shown on figure 5 , the better extraction was achieved from nitrate medium. These results may be attributed to the stronger complexion nature of sulfate anion, the formation of the complexes $\mathrm{CuSO}_{4}$ not extractible, which would reduce the concentration of $\mathrm{Cu}^{2+}$ and thus decrease their extraction[11]. Therefore, in the presence of non-coordinating anions (nitrate) the efficiency of the extraction process seems to be in favor of copper ions.

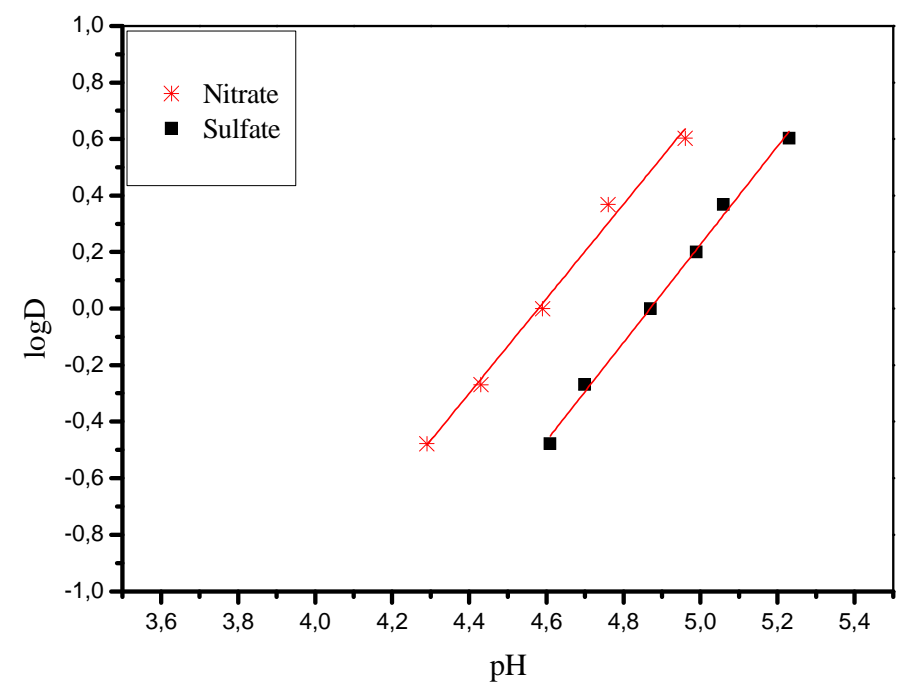

Fig.5. Effect of anion type on the copper extraction with salicylideneaniline

$$
[\mathrm{HL}]=0.02 \mathrm{M},\left[\mathrm{Cu}^{+2}\right]=1.57 \times 10^{-3}
$$

\subsubsection{Visible spectroscopic studies of extracted species}

The visible spectrum of the loaded organic phase was performed in 1-octanol (figure 6). Copper complex shows an absorbance in the $665 \mathrm{~nm}$ which indicated to octahedral geometry coordination of the extracted species. In this study, it was found that two molecules of salicylideneaniline are coordinated with the central copper ion; water molecules would complete the coordination sphere so that the copper ion could obtain a stable structure. On the basis of this interpretation, the plausible structure of the copper complex $\mathrm{CuL}_{2} \cdot 2 \mathrm{H}_{2} \mathrm{O}$ may be written as shown in figure 7. These results are similar to those which are obtained by Kriza and Spinu [12] on the extraction of copper(II) using $\mathrm{N}$-[2-thienylmethylidene]-1-propanamine. 


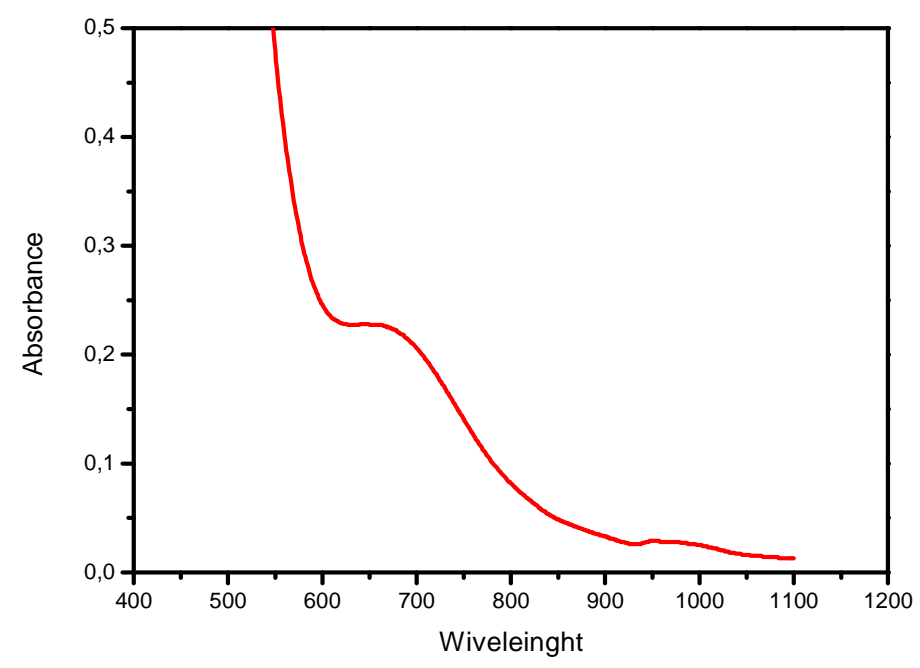

Fig.6. Visible spectrum of copper complex in 1-octanol

\subsubsection{Infrared Spectra of HL and their metal complexe}

The characteristic vibrational frequencies have been identified by comparing the spectra of the complex with their free ligand. The important IR spectral data of the free ligand and their copper(II) complex are presented in Table 3.

Table 3. Characteristic IR bands $\left(\mathrm{cm}^{-1}\right)$ of salicylideneaniline and metal complex dissolved in 1-octanol.

\begin{tabular}{cccccc}
\hline Compound & $\boldsymbol{v}(\mathbf{O H})$ & $\boldsymbol{v}(\mathbf{C}=\mathbf{N})$ & $\boldsymbol{v}(\mathbf{C}=\mathbf{C})$ & $\boldsymbol{v}(\mathbf{M}-\mathbf{N})$ & $v(\mathbf{M - O})$ \\
\hline $\mathbf{H L}$ & 3435 & 1635 & 1480 & - & - \\
$\begin{array}{c}\text { Copper(II) } \\
\text { complex }\end{array}$ & 3498 & 1611 & 1395 & 730 & 550 \\
$(\mathbf{H L}+\mathbf{C r}(\mathbf{I I I}))$ & 3432 & 1633 & 1479 & - & - \\
\hline
\end{tabular}

The vibrations of the phenolic- $\mathrm{OH}$ and imine $(\mathrm{C}=\mathrm{N})$ groups belong to salicylideneaniline compound have been observed at 3435 and $1635 \mathrm{~cm}^{-1}$, respectively $[13,14]$. Bands in the $1480-1395 \mathrm{~cm}^{-1}$ range are assigned to $v(C=C)$ vibrations of aromatic structure [15]. After the complexation reaction, the imine $(\mathrm{C}=\mathrm{N})$ band is shifted to lower frequencies $\left(1611 \mathrm{~cm}^{-1}\right)$ in the complex indicating that it has been affected upon coordination to the metal ions and reduced intensity of these bands. In addition, medium intense broad band's centered at $3380-3446 \mathrm{~cm}^{-1}$ in the complex assigned to coordinated water [10]. Also, the bands in the 
554-532 and $710-760 \mathrm{~cm}^{-1}$ range can be attributed to the $\mathrm{M}-\mathrm{O}$ and $\mathrm{M}-\mathrm{N}$ stretching modes respectively $[8,16]$. The plausible stuctrure of extracted species shows in figure. 7

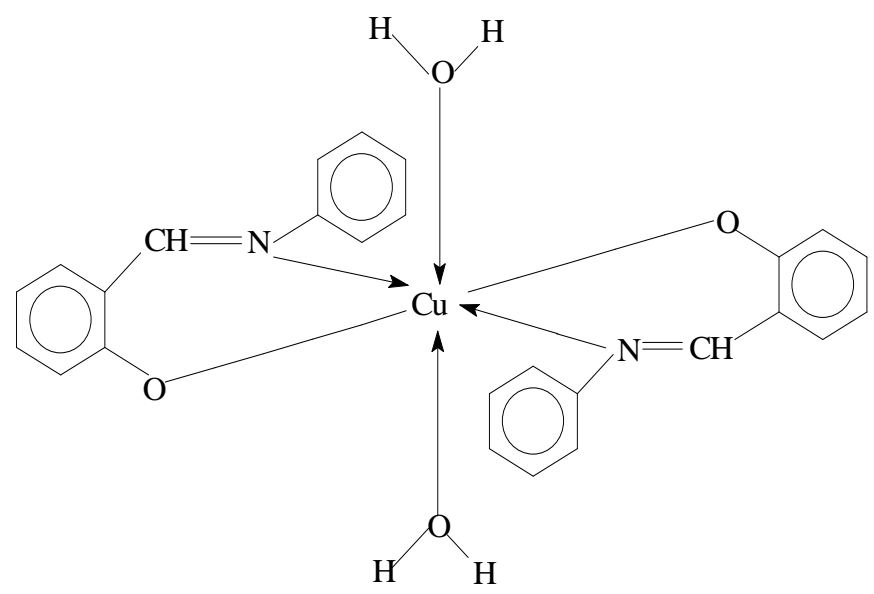

Fig.7. The plausible structure of the complex $\mathrm{CuL}_{2} \cdot 2 \mathrm{H}_{2} \mathrm{O}$

\subsubsection{Thermodynamic studies of copper(II) extraction with salicylideneaniline}

\section{in 1-octanol}

The free energy $\left(\Delta \mathrm{G}^{\circ}\right)$ was calculated for 1-octanol at constant temperature $\mathrm{T}=298.2 \mathrm{k}$. The $\Delta \mathrm{G}^{\circ}$ is expressed by the following equation $[2,17]$.

$$
\Delta \mathrm{G}^{\circ}=-2.303 \mathrm{RT} \log \mathrm{K}_{\mathrm{ex}}
$$

Where, $\mathrm{R}$ is the universal gas constant $\left(8.314 \mathrm{~J} / \mathrm{mol}^{\cdot} \mathrm{K}\right)$; $\mathrm{T}$ is the thermodynamic temperature and $\mathrm{K}_{\mathrm{ex}}$ is the extraction constant. The $\left(\Delta \mathrm{G}^{\circ}=33.11 \mathrm{~kJ} / \mathrm{mol}\right)$ value is positive. The positive value of $\left(\Delta \mathrm{G}^{\circ}\right)$ indicated that the copper(II) extraction with salicylideneaniline didn't occur spontaneously in 1-octanol. Similar results are obtained by many authors. Huff and Otu [18] studied the extraction of $\mathrm{Ni}^{2+}$ from the aqueous medium by the mono-2-ethylhexyl phosphoric acid (H2MEHP) dissolved in o-xylene. These authors showed that the extraction process of $\mathrm{Ni}^{2+}$ is not spontaneous $\left(\Delta \mathrm{G}^{\circ}=0.2 \mathrm{~kJ} / \mathrm{mol}\right)$.

\subsection{Analysis of the extraction equilibrium of chromium(III) with salicylideneaniline in 1-octanol}

In the aim to compare the solvent extraction of divalent and trivalent metal ions, a series of chromium(III) extractions was performed using salicylideneaniline diluted in 1-octanol. Studies on the effect of initial metal concentration, $\mathrm{pH}$ of aqueous phase and extraction agent concentration on the extraction process were investigated by making a series of chromium(III) 
extractions for different concentrations $(0.005 \mathrm{M}$ to $2 \mathrm{M})$ of salicylideneaniline. The initial concentration of chromium(III) in the aqueous phase were also varied from $0.96 \times 10^{-3} \mathrm{M}$ to $10^{-2} \mathrm{M}$. The $\mathrm{pH}$ of aqueous phase was also varied from 3 to 11 by adding the necessary amount of $0.1 \mathrm{M} \mathrm{NaOH}$. We are observed that chromium(III) was not extracted by salicylideneaniline under these conditions.

\subsubsection{IR spectra analysis}

Characteristic IR bands of the loaded organic phase after several hours of phase contacting $(\mathrm{HL}+\mathrm{Cr}(\mathrm{III}))$ were presented in Table 3. As seen in Table 3 , the imine $(\mathrm{C}=\mathrm{N})$ band rest approximately at constant frequency indicating that it hasn't affected any coordination to the chromium ions. In addition, the bands of the $\mathrm{M}-\mathrm{N}$ and $\mathrm{M}-\mathrm{O}$ weren't appears in the IR spectrum of loaded organic phase.

The results obtained (Table 3) show that chromium(III) is not extracted by salicylideneaniline dissolved in 1-octanol. This study allows suggesting that the absence of extraction of chromium with salicylideneaniline diluted in 1-octanol; would be due to hydrolysis of the metal in the aqueous phase at $\mathrm{pH}$ values below those required for extraction. In addition, it was attributed to an encumbered steric effect which makes it difficult to attach two or more ligands to the same ion. Also these results may depend on atom chromium size. The radius

atom of copper and chromium are $1.45 \AA$ á and 1.66 Á respectively. Chromium(III) having big atom size (radius) would encumber the coordination sites in the ligand and would, perhaps, prevent the complexation of metal ion. On the other hand, salicylideneaniline in 1-octanol extracted capably copper(II) which have small atom size (radius). In this case copper(II) can be coordinated with two or more ligands to obtain a stable structure of extracted species. Clearly, atom metals size is a factor which must be considerate when choosing extractants for solvent extraction studies. A similar result was obtained by Preston [19]] on the solvent extraction of chromium(III) with carboxylic acids in xylene. This author reported that chromium(III) was not extracted by either Versatic ${ }^{\circledR} 10$ or naphthenic acid.

\section{CONCLUSION}

The experimental data obtained in this work show that the salicylideneaniline can be successfully used to remove the heavy metal ions such as copper (II) from aqueous solutions 
(as shown in Table 1). An increase in the $\mathrm{pH}$ of aqueous phase and salicylideneaniline concentration has a favorable effect on the extraction process of copper (II). Also it was found that the better extraction of copper was achieved from nitrate medium. The proposed procedure has some advantages: simple and rapid; the higher capacity to extract copper ion; the shorter time for the extraction process. Salicylideneaniline extracts copper(II) as a monomeric extracted species from nitrate medium according to the following stoichiometric relations.

$$
\mathrm{Cu}_{\mathrm{aq}}^{2+}+2(\mathrm{HL})_{\mathrm{org}} \stackrel{\mathrm{K}_{\mathrm{ex}}}{\rightleftharpoons} \mathrm{CuL}_{2, \mathrm{org}}+2 \mathrm{H}^{+}
$$

In the other hand salicylideneaniline in organic phase unable to extracted chromium(III) from nitrate medium in the $\mathrm{pH}$ range of 3 - 11. The absence of extraction with salicylideneaniline would be due to hydrolysis of the metal in the aqueous phase at $\mathrm{pH}$ values below those required for extraction.

\section{REFERENCES}

[1] Parhi P K, Padhan E, Palai A K, Sarangi K, Nathsarma K C, Park K H. Separation of Co (II) and Ni (II) from the mixed sulphate/chloride solution using NaPC-88A. Desalination, 2011, 267, 201-208

[2] Guerdouh A, Barkat D. Thermodyn Catal. 2015, 6: 148. doi:10.4172/2157-7544.1000148

[3] Abd El-Halim H F, Mohamed Omar M, Genidy Mohamed G, Sayed M A E E. Spectroscopic and biological activity studies on tridentate Schiff base ligands and their transition metal complexes. European Journal of Chemistry, 2011, 2 178-188

[4] Dubey R K, Dubeya U K, Mishrab. C M. Synthesis and physicochemical characterization of some Schiff base complexes of chromium(III). Indian Journal of Chemistry, 2008, 47A, $1208-1212$

[5] Cegłowski, M., Schroeder, G. Preparation of porous resin with Schiff base chelating groups for removal of heavy metal ions from aqueous solutions. Chemical Engineering Journal, 2015, $263,402-411$. 
[6] Barkat D, Tayeb A, Benabdellah T, Derriche Z. Extraction par solvant du zinc en milieu sulfate par le melange: 1-Phenyl-3-methyl-4-benzoylpyrazol-5-one/methylisobutylcetone. J.Soc. Alg .Chem, 2001, 11, 149-158

[7] Al Zoubi W, Kandil F, Chebani M K. Arabian Journal of Chemistry, 2011 doi:10.1016/j.arabjc.2011.06.023

[8] S. Almi, R. Benakcha, Barkat D. extraction behavior of copper(II) with salicylideneaniline and salicylidene toluidine isomers in chloroform from sulfate medium. synthesis and Reactivity in Inorganic, Metal-Organic, and Nano-Metal Chemistry, 2015, 46, 274-279

[9] Hurwitz M D. US Parent 2,582,128. Chem. Abstr, 1952, 46, 8146

[10] Gokce C, Gup R. Synthesis, characterization and DNA interaction of new copper(II) complexes of Schiff base-aroylhydrazones bearing naphthalene ring. Journal of photochemistry and photobiology. B, Biology, 2013, 122, 15-23

[11] Barkat D, Kameche M, Tayeb A, Benabdellah T, Derriche Z. Ionic strength effect on the liquid-liquid extraction of zinc(II) and cadmium(II) from sulphate medium by 1-phenyl-3-methyl-4-benzoylpyrazol-5-one in chloroform. Phys. Chem. Liq., 2004, 42, 53-61 [12] Kriza A, Spinu C. Co (II), Ni (II) and Cu (II) complexes of bidentate Schiff bases. Acta Chim. Slov, 2000, 47, 179-185

[13] Al-Ne'aimi M M, Al-Khuder M M. Synthesis, characterization and extraction studies of some metal (II) complexes containing (hydrazoneoxime and bis-acylhydrazone) moieties. Spectrochimica acta. Part A, Molecular and biomolecular spectroscopy, 2013, 105, 365-373 [14] Al Zoubi W, Kandil F, Chebani M K. The synthesis of (N2O2S2)-Schiff base ligands and investigation of their ion extraction capability from aqueous media. Spectrochimica acta. Part A, Molecular and biomolecular spectroscopy, 2011, 79, 1909-1914

[15] Kedy S, Almhna N, Kandil F. Synthesis and characterization of new macrocyclic schiff bases by the reaction of: 1,7-Bis (6-methoxy-2-formylphenyl)-1,7-dioxaheptane and their use in solvent extraction of metals. Arabian Journal of Chemistry, 2015, 8, 93-99

[16] Kocyigit O, Kursunlu A N, Guler E. Complexation properties and synthesis of a novel Schiff base with triphenylene nucleus. Journal of hazardous materials, 2010, 183, 334-340

[17] GR C. Choppin GR Complexation of metal ions, in: Rydberg J, Cox M, Musikas, Choppin GR (Eds.) Solvent Extraction Principles and Practice, Marcel Dekker Inc., USA. 2004. 
[18] Huff M M, Otu E O. Solvent Extraction and Ion Exchange, 2004, 22(4), 695-712

[19] Preston J S. Solvent extraction of metals by carboxylic acids. Hydrometallurgy, 1985, 14, $171-188$

\section{How to cite this article:}

Guerdouh A and Barkat D. Recovery of copper(II) and chromium(III) from nitrate medium with salicylideneaniline dissolved in 1-octanol. J. Fundam. Appl. Sci., 2016, 8(2), 387-400. 